\title{
Observações recentes sobre o gasto em Ciência \& Tecnologia no Brasil
}

\author{
Armando Dalla Costa* \\ Walter Tadabiro Shima ${ }^{* *}$ \\ Bruno Reinoso Hybner ${ }^{* * *}$
}

Investimentos em Ciência e Tecnologia (C\&T), em educação e na infra-estrutura podem se tornar o ponto essencial de diferenciação entre países que têm condições de ter um crescimento econômico-social sustentado dos demais. O objetivo deste texto é apresentar os dados de investimentos em C\&T no Brasil e fazer uma comparação com outros países selecionados. Analisando o conjunto das informações, ressalta-se a necessidade de um investimento maior tanto por parte do setor público como da iniciativa privada, no sentido de dotar o país de um sistema que dê suporte a um desenvolvimento econômico sustentado e de longo prazo.

No sentido de aumentar estes investimentos, os senadores aprovaram, no dia 18 de abril de 2006, o substitutivo ao Projeto de Lei do Senado (PLS) 85/01 que regulamenta o Fundo Nacional de Desenvolvimento Científico e Tecnológico (FNDCT). O projeto precisava ser sancionado pelo presidente da República, que o vetou, seguindo orientação da Advocacia Geral da União. O ponto principal do PLS era reduzir o contingenciamento do FNDCT de $60 \%$ para $40 \%$, o que poderia representar um aporte adicional de $\mathrm{R} \$ 400$ milhões para os fundos setoriais em 2006 (ABIPTI, 2006).

O FNDCT foi criado em 1969 para financiar os projetos da área de Ciência e Tecnologia no Brasil ${ }^{43}$. Todos os recursos dos fundos setoriais (FS) estão alocados nele, mas estão longe de serem os ideais para garantir o desenvolvimento do país. Os recursos para C\&T no Brasil são estimados em 1\% do PIB (nos países desenvolvidos, em média, o investimento equivale a 3\% do PIB). No entanto, os recursos dos FS em 2004 e 2005 representaram respectivamente 0,035 e $0,043 \%$ do PIB. Para se chegar a um gasto estimado

\footnotetext{
* Doutor pela Université de Paris III (Sorbonne-Nouvelle). Professor do Departamento de Economia e Coordenador do Núcleo de Pesquisa em Economia Empresarial da UFPR. Endereço eletrônico: adjcosta@,uol.com.br.

** Doutor em Economia pelo IE/UFRJ. Professor do Departamento de Economia da UFPR. Endereço eletrônico: waltershima@ufpr.br

*** Graduando em Ciências Econômicas pela UFPR. Bolsista do CEPEC. Endereço eletrônico: bru_reinoso@yahoo.com.br

43 Em 1968-1969, o Plano Estratégico de Desenvolvimento (PED) do governo militar propôs uma política explícita de ciência e tecnologia ao nível federal, com o Sistema Nacional de Desenvolvimento Científico e Tecnológico (SNDCT). O FNDCT foi criado para financiar esse sistema. Nesse sistema, três Planos Básicos de Desenvolvimento Científico e Tecnológico foram criados: PBDCT I, II e III de 1973 a 1985. Muitas outras instituições públicas e programas relacionados a P\&D em diferentes áreas podem ser numerados dentro do II PBDCT.
} 
em 1\%, considera-se o investimento na manutenção das universidades federais (cerca de $0,5 \%$ do PIB em 2004) e também nas estaduais públicas, assim como nos institutos públicos de pesquisa (Coggiola \& Oliveira, 2006) (gráfico 1)).

\section{Gráfico 1. Investimentos do Brasil em P\&D, em \% do PIB no período 2000-2004}

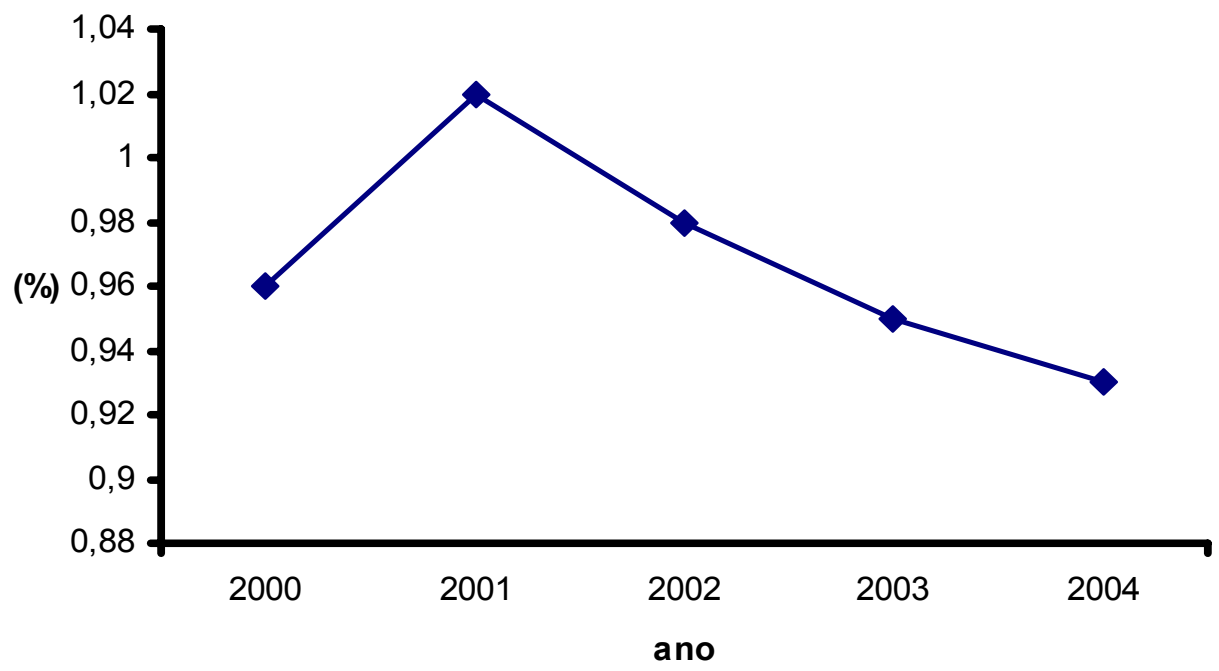

Fonte: MCT.

No Conselho Nacional de Desenvolvimento Científico e Tecnológico (CNPq), uma das principais agências financiadoras do sistema de C\&T, o orçamento, que era de $\mathrm{R} \$ 742$ milhões em 1998, chegou a R $\$ 525$ milhões em 2002, uma queda da ordem de 8,30\% ao ano. Já para a Coordenação de Aperfeiçoamento de Pessoal de Nível Superior (CAPES), os valores baixaram de $\mathrm{R} \$ 598$ milhões para $\mathrm{R} \$ 460$ milhões, no mesmo período, o que equivale a uma queda de 6,4\% ao ano. Em valores totais, incluindo os gastos gerais feitos por todos os ministérios, o dispêndio em C\&T foi de $\mathrm{R} \$ 3$ bilhões em 2002, uma redução drástica em relação aos valores de 1996, quando a União chegou a investir R \$ 3,6 bilhões. Considera-se que esses valores não estão corrigidos pela inflação do período, pois se levar em conta esta hipótese, a taxa de queda anual se torna ainda mais dramática.

Entre 1998 e 2002, o total aplicado pelos Estados em P\&D baixou de R\$1,71 para R\$ 1,33 bilhão. Entretanto, sua participação no total dos gastos em P\&D, conforme pode ser visto no gráfico 2 para o período de 2000 a 2004, reduziu de 0,40\% para 0,39\% apenas. Juntando o resultado desse segmento, com o desempenho do Governo Federal, pode-se notar a confirmação do predomínio da esfera pública na realização dos dispêndios em P\&D frente ao setor privado. Prova é, que no intervalo de tempo em questão, a participação das empresas neste quesito reduziu-se quase pela metade. 


\section{Gráfico 2. Gastos em P\&D realizados pelo Governo Federal, governos estaduais e empresas no período 2000-2004}

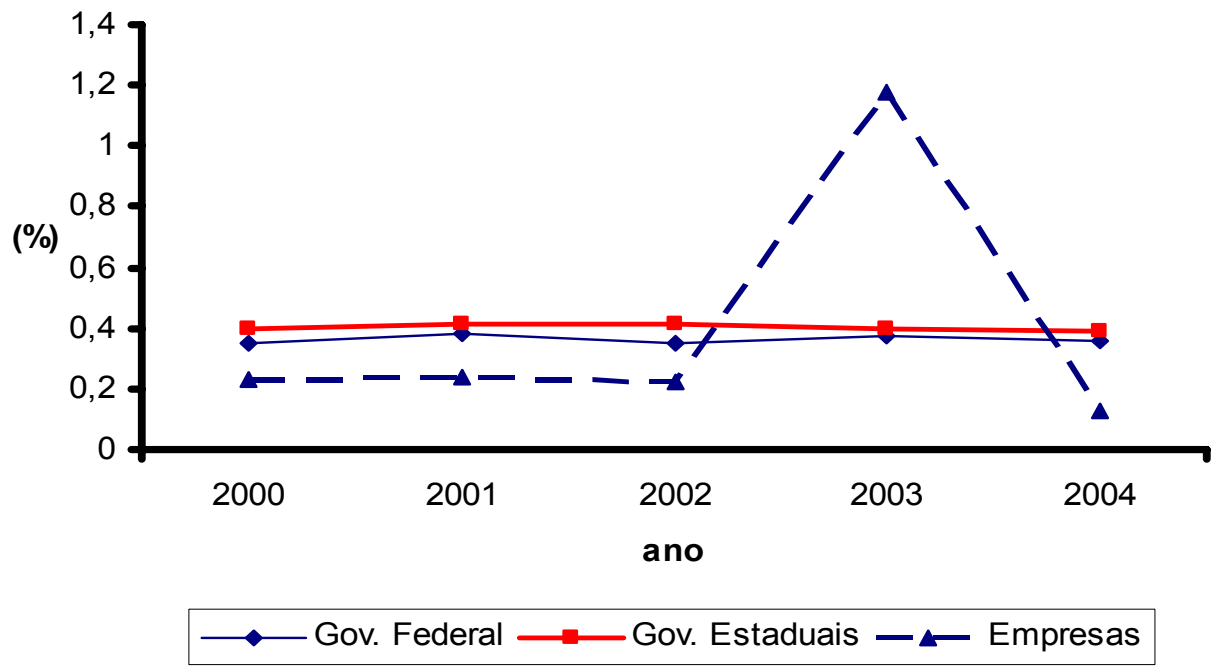

Fonte: MCT

Em países como o Japão, os EUA, a França e a Alemanha, os gastos em C\&T passam de 2,5\% do PIB, considerando o investimento público e privado. A tendência no Brasil foi de queda entre 2000 e 2004. Depois de atingir 1,02\% em 2001, caiu para 0,98; 0,95 e 0,93\% nos respectivos anos subseqüentes, até 2004, como pôde ser visto no gráfico 1 . A notícia de 11 de maio de 2006 sobre o veto do presidente à lei que descontingenciava o FNDCT aumenta as dificuldades para a recuperação do percentual dos dispêndios em P\&D e C\&T para os próximos anos. A promessa de elevar o investimento em P\&D a $2 \%$ do PIB até o final de 2006, feita pelo candidato Lula e reafirmada na presidência, não será cumprida ${ }^{44}$.

Analisando-se os gastos de países selecionados, percebe-se melhor o quanto o Brasil está longe dos investimentos dos concorrentes, conforme pode ser visto no gráfico 3, o qual mostra a intensidade de dispêndios em P\&D. Nota-se também, pelo gráfico 4, que ainda os gastos em P\&D são predominantemente feito pelo Governo ${ }^{45}$. Nesse mesmo contexto, verifica-se que em países mais desenvolvidos, como por exemplo, os pertencentes a OCDE, predomina o gasto privado.

44 “Os gastos em C\&T serão tratados não como custos correntes, mas como investimento num futuro melhor para o país. A grande meta instrumental dessa política será aumentar progressivamente o percentual do PIB aplicado em P\&D, saltando de $1 \%$ para algo próximo de $2 \%$ no final do mandato do atual governo". A afirmação encerrava o primeiro parágrafo do capítulo "Ciência e Tecnologia para o Desenvolvimento Nacional", que integra a primeira mensagem enviada ao Congresso Nacional pelo presidente Lula no início de 2003.

45 Os gastos do governo em P\&D abrangem os gastos realizados diretamente pelo próprio governo e os dispêndios realizados pela educação superior. 
Gráfico 3. Intensidade de gastos em $P \& D$, por países selecionados, em valores correntes e em porcentagem do PIB, em 2001

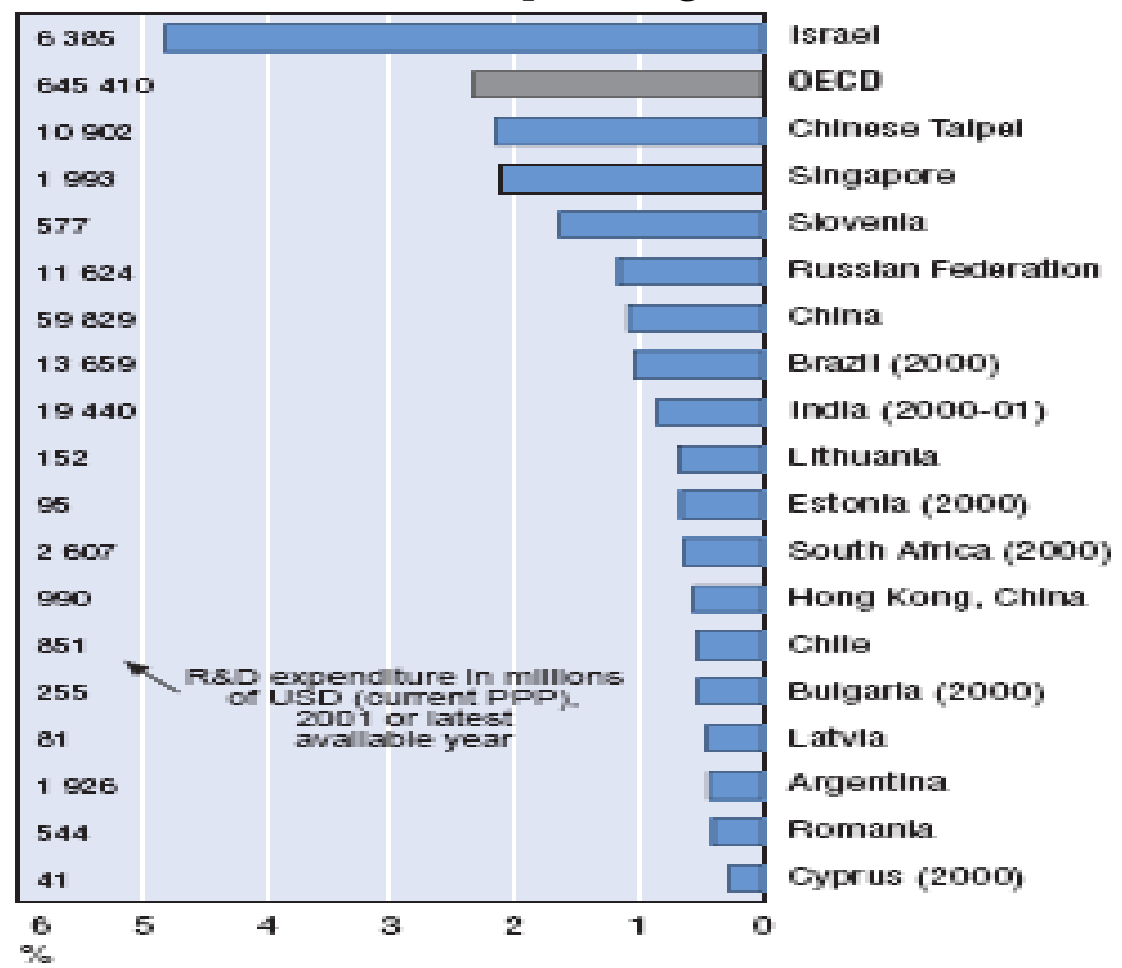

Fonte: OECD Science, Technology and Industry Scoreboard, 2003.

Nota: Valores correntes estão em milhões de dólares.

Gráfico 4. Gastos em P\&D de países selecionados por segmento (participação no total nacional em 2001)

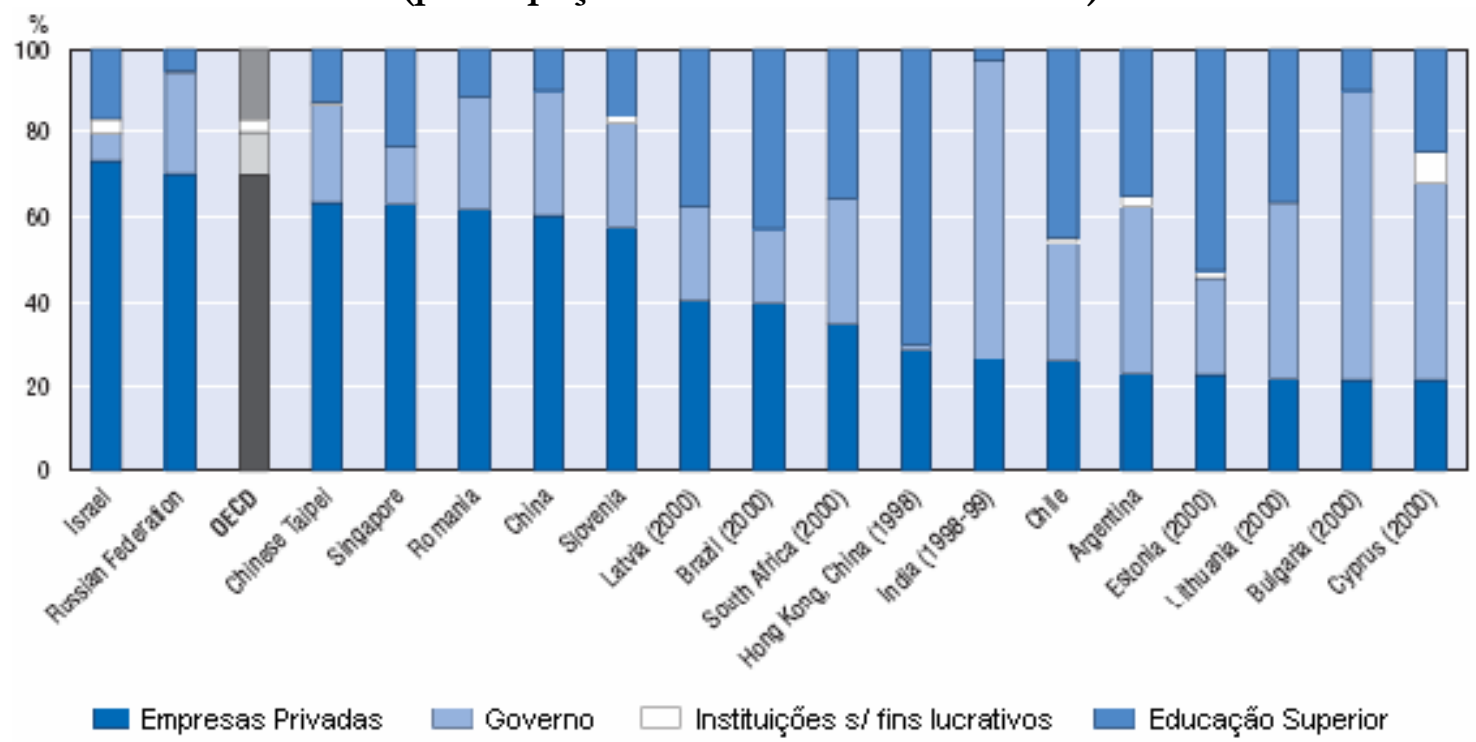

Fonte: OECD Science, Technology and Industry Scoreboard, 2003. 
$\mathrm{Na}$ última década, a distância entre os EUA, os "desenvolvidos" em geral e os latinoamericanos cresceu ainda mais. Enquanto no Brasil o gasto em C\&T por habitante é de cerca de US\$73, em países como a França, os valores atingem os US\$ 500 e, nos EUA, chegam a US\$1.000.

Numa pesquisa realizada pela consultoria Booz Allen Hamilton e a Insead, com dados de 2005, junto a 186 companhias de 19 países e 17 setores, cujas despesas anuais em P\&D somaram US\$ 76 bilhões, ficou claro que o Brasil tem menos restrições legais e regulatórias do que a China, além de contar com um mercado interno maior que o da Índia. Os gargalos de infra-estrutura não são piores do que os encontrados em outros países emergentes. Apesar disso, foram China e Índia as que mais atraíram investimentos em P\&D. Juntos, os dois detêm 13,9\% dos centros de P\&D de multinacionais. Em 1990, a participação conjunta era de 3,4\%. Nos últimos 30 anos, a presença de centros de pesquisa longe das sedes das companhias cresceu de $44 \%$ para $66 \%$.

O trabalho mostra não apenas que China e Índia foram os principais beneficiários dessa tendência, mas que devem ganhar ainda mais: 77\% dos novos centros de P\&D planejados até 2007 serão destinados a um destes países. Até o final de 2007, ambos terão $31 \%$ da força de trabalho mundial em P\&D. Em 2004, tinham 19\%.

Estes dados, no entanto, não apontam para uma descentralização de $\mathrm{P} \& \mathrm{D}$ dos países desenvolvidos em direção aos demais. No que se refere à tecnologia de ponta, cerca de $75 \%$ das empresas têm capacidade de criar suas tecnologias-chave junto às respectivas sedes. Em contrapartida, 55\% dos centros de pesquisa alocados em outros países fazem apenas adaptações ou possuem conhecimento em uma área específica. Como conclusão, pode-se dizer que a descentralização mundial em $\mathrm{P} \& \mathrm{D}$ não afeta a concentração do conhecimento de ponta nos países centrais, nem a dependência tecnológico-científica da periferia.

Uma das causas que dificulta os investimentos em P\&D no país é a educação. Segundo estudo de mercado de José Pastore, o país possui 12\% de analfabetos absolutos; $60 \%$ de analfabetos funcionais (que têm dificuldades para entender o que lêem e fazer cálculos); conta com 9\% de estudantes cursando ensino superior; investe 5,5\% do PIB em educação; e requer, de maneira estimada, 12 anos para alcançar um cenário adequado de capacitação.

A exceção é a pós-graduação, graças a uma experiência de 40 anos, que cresce a uma taxa de $14 \%$ ao ano. Fruto deste processo existe hoje 130 mil pós-graduandos no país, compostos de $2 / 3$ de mestrandos e $1 / 3$ de doutorandos (dados da CAPES). Deste total, 
apenas $1 / 3$ recebe bolsa, sendo que o CNPq e a CAPES são responsáveis por $85 \%$ destas bolsas (a iniciativa privada investe pouco nesta área). Outro dado é que nas universidades brasileiras, que possuem 32 mil docentes orientando estes 130 mil pós-graduandos, há apenas $20 \%$ do quadro docente com doutorado, dedicado à pesquisa e à formação de novos professores-pesquisadores.

Outro dado que chama atenção é a destinação dos recursos públicos, analisados por região, instituições públicas, privadas e outras (sem identificação quanto a público-privado) (tabela 1).

Tabela 1. Destino dos recursos dos FS quanto às instituições em 2004

\begin{tabular}{lc|c|c|c}
\hline \multicolumn{1}{c|}{ Região } & Recursos FS & $\begin{array}{c}\text { Instituições } \\
\text { Públicas }(\%)\end{array}$ & $\begin{array}{c}\text { Instituições } \\
\text { Privadas }(\%)\end{array}$ & $\begin{array}{c}\text { Outras } \\
\text { Instituições (\%) }\end{array}$ \\
\hline Norte & $11.637 .979,37$ & 10 & 90 & 0 \\
Centro Oeste & $30.374 .239,30$ & 55 & 43 & 2 \\
Nordeste & $52.226 .829,30$ & 19 & 77 & 4 \\
Sul & $77.173 .820,61$ & 7 & 93 & 0 \\
Sudeste & $164.635 .005,66$ & 19 & 78 & 4 \\
BRASIL & $336.047 .874,24$ & 19 & 78 & 3 \\
\hline
\end{tabular}

Fonte: Finep

Pelos dados, percebe-se que, no tocante a repasses de recursos públicos, o setor privado é claramente privilegiado. Quase todo o volume dos recursos do FNDCT é representado pelos fundos setoriais. Isto significa que, além de não poder financiar adequadamente áreas importantes como a pesquisa básica em ciências humanas e sociais, a biomédica, a química fina, a física de novos materiais, a matemática aplicada, a genômica e proteômica da biodiversidade, não haverá recursos para atender a programas importantes de inclusão social, como o do biodiesel, a inclusão digital e outros. Ademais, nota-se uma nova dinâmica do Sistema de Inovação na medida em que a dinâmica dos FS implica captação forte junto aos setores privados, bem como sua aplicação nesses mesmos setores.

Pensando numa perspectiva teórica da Triple Helix (Etzkowitz \& Leydesdorff, 2000), pode-se afirmar que nessa nova dinâmica o Brasil sai de uma dimensão em que uma das hélices (o Estado) tem mais peso e abrange as demais (indústria e universidade) para um equilíbrio de transição permanente entre as instituições que compõe cada uma das hélices. Ou seja, as instituições atuam de forma integrada a ponto de formarem instituições híbridas, que é o que compõe a coluna Outras Instituições (tabela 1), além de terem uma forte e equilibrada ação de P\&D, seja em conjunto e/ou separadas.

Por último, lembre-se que a Lei de Inovação Tecnológica, recentemente regulamentada (ver boletim Economia \& Tecnologia, vol. 02 de jul./ago. de 2005) prevê o aporte 
de recursos públicos e não-reembolsáveis diretamente às empresas. A prioridade é para as pequenas e microempresas e para a Política Industrial, Tecnológica e de Comércio Exterior. O valor da subvenção será definido anualmente por meio de portaria interministerial e terá como fonte de recursos o FNDCT.

\section{Referências Bibliográficas}

Associação Brasileira das Instituições de Pesquisas Tecnológicas (ABIPTI). Disponível em: http://www.gestaoct.org.br/eletronico/jornais/numero479.htm. Acesso em: jul. de 2006.

COGGIOLA, Osvaldo; OLIVEIRA, Marinalva de, PAIVA, Jacob. "O veto à regulamentação do Fundo Nacional de Desenvolvimento Científico e Tecnológico e os Fundos Setoriais", veiculado no site do Sindicato Nacional dos Docentes das Instituições de Ensino Superior. Acesso em: jun. de 2006

DAHLMAN, C. J.; FRISCHTAK, C.. National system supporting technical advance in industry: the brazilian experience. In: Nelson, R. (ed.). National innovation system: a comparative analysis. Oxford: NewYork, 1993. cap. 13, p. 414-450.

ETZKOWITZ, H. \& LEYDESDORFF. L.. The dynamics of innovation: from National Systems and "Mode 2" to a Triple Helix of university-industry-government relations. Research Policy 292000 109-123

OECD Science, Technology and Industry Scoreboard, 2003.

PASTORE, J. (2004). “Falta muita educação”. In: Revista CNT, nov.

SILVA FILHO, A. M.. “Inovação para o desenvolvimento humano: o 'negócio' das empresas no Brasil". Disponível em: http://www.espacoacademico.com.br/061/61 silvafilho.htm Acesso em: jun. de 2006. 
